\title{
Case Report: Dual nebulised antibiotics among adults with \\ cystic fibrosis and chronic Pseudomonas infection [version 1;
}

\section{peer review: 3 approved with reservations]}

\author{
Nina Mann1, Shirley Murray¹, Zhe Hui Hoo(D1,2, Rachael Curley1,2, \\ Martin J. Wildman ${ }^{1,2}$ \\ ${ }^{1}$ Sheffield Adult Cystic Fibrosis Centre, Northern General Hospital, Sheffield, S5 7AU, UK \\ ${ }^{2}$ School of Health and Related Research (ScHARR), University of Sheffield, Sheffield, S1 4DA, UK
}

\begin{tabular}{l} 
V1 First published: 01 Dec 2017, 6:2079 \\
https://doi.org/10.12688/f1000research.13298.1 \\
Latest published: 28 Feb 2018, 6:2079 \\
https://doi.org/10.12688/f1000research.13298.2 \\
\hline
\end{tabular}

\section{Abstract}

Pulmonary exacerbations in adults with cystic fibrosis (CF) and chronic Pseudomonas aeruginosa (Psae) infection are usually treated with dual intravenous antibiotics for 14 days, despite the lack of evidence for best practice. Intravenous antibiotics are commonly associated with various systemic adverse effects, including renal failure and ototoxicity. Inhaled antibiotics are less likely to cause systematic adverse effects, yet can achieve airway concentrations well above conventional minimum inhibitory concentrations. Typically one inhaled antibiotic is used at a time, but dual inhaled antibiotics (i.e. concomitant use of two different inhaled antibiotics) may have synergistic effect and achieve better results in the treatment of exacerbations. We presented anecdotal evidence for the use of dual inhaled antibiotics as an acute treatment for exacerbations, in the form of a case report. A female in her early thirties with CF and chronic Psae infection improved her $\mathrm{FEV}_{1}$ by $5 \%$ and $2 \%$ with two courses of dual inhaled antibiotics to treat exacerbations in 2016. In contrast, her $\mathrm{FEV}_{1}$ changed by $2 \%,-2 \%, 0 \%$ and $2 \%$, respectively, with four courses of dual intravenous antibiotics in 2016. Baseline FEV 1 was similar prior to all six courses of treatments. The greater FEV 1 improvements with dual inhaled antibiotics compared to dual intravenous antibiotics suggest the potential role of using dual inhaled antibiotics to treat exacerbations among adults with CF and chronic Psae infection, especially since a greater choice of inhaled anti-pseudomonal antibiotics is now available. A previous study in 1985 has looked at the concomitant administration of inhaled tobramycin and carbenicillin, by reconstituting antibiotics designed for parenteral administration. To our knowledge, this is the first literature to describe the concomitant use of two different antibiotics specifically developed for delivery via the inhaled route.

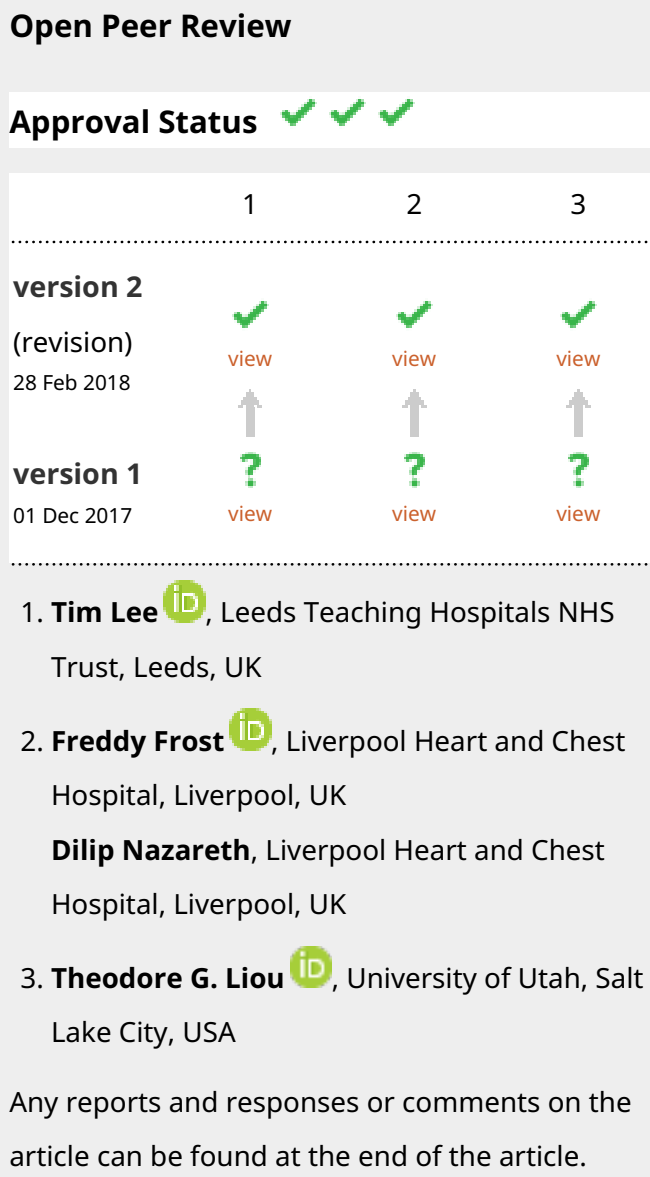




\section{Keywords}

Cystic fibrosis, nebuliser therapy, pulmonary exacerbations, Pseudomonas aeruginosa

\section{Corresponding author: Martin J. Wildman (martin.wildman@sth.nhs.uk)}

Author roles: Mann N: Data Curation, Formal Analysis, Investigation, Methodology, Validation, Visualization, Writing - Original Draft Preparation, Writing - Review \& Editing; Murray S: Data Curation, Formal Analysis, Investigation, Methodology, Validation, Visualization, Writing - Original Draft Preparation, Writing - Review \& Editing; Hoo ZH: Data Curation, Formal Analysis, Investigation, Methodology, Supervision, Validation, Visualization, Writing - Review \& Editing; Curley R: Data Curation, Formal Analysis, Investigation, Methodology, Validation, Writing - Review \& Editing; Wildman MJ: Conceptualization, Data Curation, Formal Analysis, Investigation, Methodology,

Resources, Supervision, Validation, Visualization, Writing - Review \& Editing

Competing interests: No competing interests were disclosed.

Grant information: The author(s) declared that no grants were involved in supporting this work.

Copyright: @ 2017 Mann N et al. This is an open access article distributed under the terms of the Creative Commons Attribution License, which permits unrestricted use, distribution, and reproduction in any medium, provided the original work is properly cited.

How to cite this article: Mann N, Murray S, Hoo ZH et al. Case Report: Dual nebulised antibiotics among adults with cystic fibrosis and chronic Pseudomonas infection [version 1; peer review: 3 approved with reservations] F1000Research 2017, 6:2079 https://doi.org/10.12688/f1000research.13298.1

First published: 01 Dec 2017, 6:2079 https://doi.org/10.12688/f1000research.13298.1 


\section{Introduction}

Cystic fibrosis (CF) is a genetic condition whereby $~ 80 \%$ of mortalities are primarily due to lung disease ${ }^{1}$. People with $\mathrm{CF}$ are prone to recurrent respiratory infections (termed 'pulmonary exacerbations'), which leads to progressive lung damage and respiratory failure ${ }^{2}$. This is especially so after Pseudomonas aeruginosa (Psae) is acquired ${ }^{3}$.

Although there is a lack of evidence for best practice in treating exacerbations among adults with $\mathrm{CF}$ and chronic Psae infection ${ }^{4}$, two weeks of dual intravenous antibiotics are generally used for synergistic effect ${ }^{4,5}$. The European CF Society recommend against using inhaled antibiotics to treat exacerbations, due to concerns that increased mucus plugs during exacerbations may prevent antibiotics from reaching smaller airways ${ }^{5}$.

There is scant research on using inhaled antibiotics to treat exacerbations. A Cochrane review found only four relevant studies, with inadequate sample sizes to demonstrate efficacy ${ }^{6}$. Nonetheless, a large observational study in North America found that $\sim 24 \%$ of exacerbations are treated with inhaled antibiotics ${ }^{7}$. Inhaled antibiotics have several advantages. Systemic adverse effects e.g. allergic reactions, gastrointestinal manifestations, ototoxicity and renal failure are common with intravenous antibiotics ${ }^{8,9}$ but rare with inhaled antibiotics ${ }^{10}$. Higher antibiotic concentrations within the airways are achieved via inhaled route, which may be beneficial in overcoming resistance ${ }^{11}$. Inhaled route also overcomes difficulties associated with venous access.

Typically one inhaled antibiotic is used at a time, and someone on multiple inhaled antibiotics would alternate between those antibiotics $^{10}$. Of the four studies identified in the Cochrane review, only one study with 18 participants looked at concomitant administration of two inhaled antibiotics (tobramycin and carbenicillin) ${ }^{6}$. Yet dual inhaled antibiotics (i.e. concomitant use of two different inhaled antibiotics) may have synergistic effect, thus achieve better results. We report on an adult with $\mathrm{CF}$ and chronic Psae infection who achieved good results when treating exacerbations using dual inhaled antibiotics.

\section{Case report}

A Caucasian female in her early thirties with F508del/Class I mutation, pancreatic insufficiency and CF related diabetes also fulfilled the Leeds criteria $^{12}$ for chronic Psae infection. Despite high objective adherence to nebulised dornase alfa $2.5 \mathrm{mg}$ once daily and alternating Promixin ${ }^{\circledR} 1$ megaunit twice daily/ TOBI $^{\circledR} 300 \mathrm{mg}$ twice daily $(82.9 \%$ two years ago, $96.3 \%$ in the previous year; measured with an I-neb $\left.^{\circledR}\right)$, stable BMI around 23.1 and reasonable glycaemic control (HbA1c 47 in month 1 of the follow-up period), there was a trend of declining $\% \mathrm{FEV}_{1}$. Her annual best $\mathrm{FEV}_{1}$ was $47 \%, 44 \%$ and $42 \%$ over the previous three years. There was no evidence of allergic bronchopulmonary aspergillosis (ABPA) or other $\mathrm{CF}$ complications compromising her $\% \mathrm{FEV}_{1}$.
In month one, Promixin ${ }^{\circledR}$ was switched to nebulised AZLI ${ }^{\circledR}$ $75 \mathrm{mg}$ thrice daily. She had two courses (28 days) of intravenous antibiotics throughout the previous year. She agreed to threemonthly intravenous antibiotics in the follow-up year to try to arrest the $\mathrm{FEV}_{1}$ decline. She had 14 days of intravenous Tazocin $4.5 \mathrm{~g}$ thrice daily and colomycin 2 megaunit thrice daily in month one ( $\% \mathrm{FEV}_{1}$ improved from $38 \%$ to $40 \%$ ), and again in month $4\left(\% \mathrm{FEV}_{1}\right.$ declined from $40 \%$ to $\left.38 \%\right)$.

She felt less well with increased sputum volume and dyspnoea at the start of month six. Her $\% \mathrm{FEV}_{1}$ was $39 \%$. She agreed to try 14 days of concomitant nebulised AZLI ${ }^{\circledR} 75 \mathrm{mg}$ thrice daily and TOBI $^{\circledR} 300 \mathrm{mg}$ twice daily. Her $\% \mathrm{FEV}_{1}$ improved to $45 \%$ at day 7 and $44 \%$ at day 14 . Her symptoms resolved by day 14 .

She felt well but her $\% \mathrm{FEV}_{1}$ declined to $39 \%$ during her next clinic review at the end of month seven. She went on another 14-day course of intravenous Tazocin $4.5 \mathrm{~g}$ thrice daily and colomycin 2 megaunit thrice daily. At day 14 , her $\% \mathrm{FEV}_{1}$ remained $39 \%$. Another 14-day course of concomitant nebulised AZLI ${ }^{\circledR}$ and $\mathrm{TOBI}^{\circledR}$ was started in month 8 . Her \%FEV1 improved to $41 \%$ at day 7 and day 14, despite developing viral coryzal symptoms at day 12 . With 14 days of IV Tazocin $4.5 \mathrm{~g}$ thrice daily and tobramycin $480 \mathrm{mg}$ once daily in month 11 , her $\% \mathrm{FEV}_{1}$ improved from $39 \%$ at day 1 to $41 \%$ at day 14 .

\section{Discussion}

In this case, $\% \mathrm{FEV}_{1}$ improvement following acute treatment of exacerbations with dual inhaled antibiotics (mean $3.5 \%$ over two courses) was somewhat higher than with dual intravenous antibiotics (mean $0.5 \%$ over four courses), despite similar baseline $\% \mathrm{FEV}_{1}$. The $\% \mathrm{FEV}_{1}$ improvement also occurred despite severe background lung disease (high resolution CT in month eight showed extensive bronchiectasis and baseline $\% \mathrm{FEV}_{1}$ was $\sim 40 \%$ ).

Although she reported symptomatic improvement during her first dual inhaled antibiotics course, we did not formally measure symptomatic responses to treatments with a validated tool. The sample size is too small for null hypothesis significance testing, and regression to the mean is potentially a threat to our results. Our results are nonetheless intriguing and suggest that dual inhaled antibiotics could potentially have a role in treating exacerbations among adults with $\mathrm{CF}$ and chronic Psae infection. With the increasing number of inhaled anti-pseudomonal antibiotics available, e.g. nebulised levofloxacin ${ }^{13}$, different combinations of concomitant inhaled antibiotics can be used in the future for synergistic effect.

Like all medications, there are adverse events associated with inhaled antibiotics. There is a case report of acute respiratory distress syndrome potentially due to inhaled colistin ${ }^{14}$. However, localised adverse events with inhaled antibiotics are usually mild, e.g. bronchoconstriction which tends to resolve spontaneously within hours or can be controlled by pre-dosing with nebulised bronchodilator $^{10}$. 
High adherence to inhaled therapies probably contributed to the good clinical response from dual inhaled antibiotics observed in this case. Real-world adherence with long-term inhaled antibiotics among adults with $\mathrm{CF}$ is only $35-50 \%{ }^{15,16}$. Someone who is already struggling with a single inhaled antibiotic is unlikely to cope with dual inhaled antibiotics, thus may derive less benefit. However, adherence to short-term drug regimen tends to be higher ${ }^{17}$. Adults with $\mathrm{CF}$ might be able to summon adequate self-regulation during a 14-day dual antibiotics course to really focus on their nebuliser use ${ }^{18}$.

In conclusion, the $\% \mathrm{FEV}_{1}$ improvements observed in this case report provide anecdotal evidence that dual inhaled antibiotics could potentially be a treatment option for exacerbations among adults with $\mathrm{CF}$ and chronic Psae infection. Given the lack of good quality evidence regarding optimum exacerbations treatments and the theoretical advantages of using inhaled antibiotics, this warrants further investigations.

\section{Consent}

Written informed consent for publication of her clinical details was obtained from the patient.

\section{Competing interests}

No competing interests were disclosed.

\section{Grant information}

The author(s) declared that no grants were involved in supporting this work.
1. Elborn JS: Cystic fibrosis. Lancet. 2016; 388(10059): 2519-2531. PubMed Abstract | Publisher Full Text

2. Bhatt JM: Treatment of pulmonary exacerbations in cystic fibrosis. Eur Respir Rev. 2013; 22(129): 205-216.

PubMed Abstract | Publisher Full Text

3. Mayer-Hamblett N, Kronmal RA, Gibson RL, et al.: Initial Pseudomonas aeruginosa treatment failure is associated with exacerbations in cystic fibrosis. Pediatr Pulmonol. 2012; 47(2): 125-134.

PubMed Abstract | Publisher Full Text | Free Full Text

4. Flume PA, Mogayzel PJ Jr, Robinson KA, et al:: Cystic fibrosis pulmonary guidelines: treatment of pulmonary exacerbations. Am J Respir Crit Care Med. 2009; 180(9): 802-808.

PubMed Abstract | Publisher Full Text

5. Döring $G$, Flume $P$, Heijerman $H$, et al:: Treatment of lung infection in patients with cystic fibrosis: current and future strategies. J Cyst Fibros. 2012; 11(6): 461-479.

PubMed Abstract | Publisher Full Text

6. Ryan G, Jahnke N, Remmington T: Inhaled antibiotics for pulmonary exacerbations in cystic fibrosis. Cochrane Database Syst Rev. 2012; 12: exacerbations

PubMed Abstract | Publisher Full Tex

7. Wagener JS, Rasouliyan L, VanDevanter DR, et al: Oral, inhaled, and intravenous antibiotic choice for treating pulmonary exacerbations in cystic fibrosis. Pediatr Pulmonol. 2013; 48(7): 666-673.

PubMed Abstract | Publisher Full Text | Free Full Text

8. Peckham D, Whitaker P: Drug induced complications; can we do more? J Cyst Fibros. 2013; 12(6): 547-558.

PubMed Abstract | Publisher Full Text

9. Roehmel JF, Schwarz C, Mehl A, et al.: Hypersensitivity to antibiotics in patients with cystic fibrosis. J Cyst Fibros. 2014; 13(2): 205-211.

PubMed Abstract | Publisher Full Text
10. Quon BS, Goss CH, Ramsey BW: Inhaled Antibiotics for Lower Airway Infections. Ann Am Thorac Soc. 2014; 11(3): 425-434. PubMed Abstract | Publisher Full Text | Free Full Text

11. Conway SP: Evidence for using nebulised antibiotics in cystic fibrosis. Arch Dis Child. 1999; 80(4): 307-309.

PubMed Abstract | Publisher Full Text | Free Full Text

12. Lee TW, Brownlee KG, Conway SP, et al: Evaluation of a new definition for chronic Pseudomonas aeruginosa infection in cystic fibrosis patients. $J$ Cyst Fibros. 2003; 2(1): 29-34.

PubMed Abstract | Publisher Full Text

13. Elborn JS, Flume PA, Cohen F, et al:: Safety and efficacy of prolonged levofloxacin inhalation solution (APT-1026) treatment for cystic fibrosis and chronic Pseudomonas aeruginosa airway infection. J Cyst Fibros. 2016; 15(5): 634-640.

PubMed Abstract | Publisher Full Text

14. McCoy KS: Compounded colistimethate as possible cause of fatal acute respiratory distress syndrome. N Engl J Med. 2007; 357(22): 2310-2311. PubMed Abstract | Publisher Full Text

15. Daniels T, Goodacre L, Sutton C, et al:: Accurate assessment of adherence: selfreport and clinician report vs electronic monitoring of nebulizers. Chest. 2011; 140(2): 425-432.

PubMed Abstract | Publisher Full Text

16. Quittner AL, Zhang J, Marynchenko M, et al:: Pulmonary medication adherence and health-care use in cystic fibrosis. Chest. 2014; 146(1): 142-151. PubMed Abstract | Publisher Full Text

17. Haynes RB, McDonald HP, Garg AX: Helping patients follow prescribed treatment: clinical applications. JAMA. 2002; 288(22): 2880-2883. PubMed Abstract | Publisher Full Text

18. Baumeister RF, Bratslavsky E, Muraven M, et al:: Ego depletion: is the active self a limited resource? J Pers Soc Psychol. 1998; 74(5): 1252-1265. PubMed Abstract | Publisher Full Text 


\section{Open Peer Review}

\section{Current Peer Review Status: ? ? ?}

Version 1

Reviewer Report 08 February 2018

https://doi.org/10.5256/f1000research.14431.r29543

(C) 2018 Liou T. This is an open access peer review report distributed under the terms of the Creative Commons Attribution License, which permits unrestricted use, distribution, and reproduction in any medium, provided the original work is properly cited.

\section{Theodore G. Liou}

Department of Internal Medicine, University of Utah, Salt Lake City, UT, USA

This is a case report of a patient with CF during a 6 month period during which she was treated with multiple antibiotics in several regimens that seemed to differ with each treatment episode.

The introduction is well written and informative. The case history itself raises many questions. There are fewer details of the patient's baseline history than desired. The lack of a specific age is not typical for case reports. It would be nice to know whether her genotype was F508del homozygous or heterozygous with a second, preferably identified, mutation. The report of high adherence of the patient is open to doubt because of the poor track record of clinicians detecting non-adherence in an accurate way, and confirmation of the degree of adherence, perhaps with a medication possession report, would be helpful.

The key portion of the history detailing treatments with various antibiotics, regimens and dosing routes is interesting but lacks some key details. It is not entirely clear what triggered the more intensive 6 months. There is reference to symptoms and signs often associated with acute exacerbations, the introduction seems to focus at least in part on exacerbations, and the discussion refers to "acute treatment of exacerbations," but the patient's course is not described in a way as to identify when pulmonary exacerbations were specifically diagnosed or treated. This detracts from helping readers understand the circumstances for which different treatments were initiated.

In the discussion, the authors discuss the possible effects of dual inhaled antibiotics, but I find it difficult to associate such use with a superior outcome even on an anecdotal basis because many drugs and regimens were employed in response to what seems to have been multiple clinical situations during the 6-month case history period.

I think the report could be improved by providing more patient history prior to the 6-month period of focus, better assessment of her level of adherence, clear definition of pulmonary exacerbation as used in this patient's case and clearer description of triggers for different treatments as well as more precise descriptions of outcomes. An additional outcome to consider 
including would be the results of subsequent bacterial cultures and any changes in resistance patterns.

A study of dual inhaled antibiotics compared to intravenous would be of interest. However, there are likely to be many barriers and difficulties developing a generally usable protocol. Some mention of these barriers might be helpful to explain why such a study has not been done.

Finally, to help readers in areas of the world where trade names are not the same or the medications are not available, Promixin, Azli, Tobi, Tazocin and Coly-Mycin should be identified by their generic names in addition to the trademarked names. It would be better, I think, if they were referred to by their generic names in preference to the trade names.

Is the background of the case's history and progression described in sufficient detail? No

Are enough details provided of any physical examination and diagnostic tests, treatment given and outcomes?

No

Is sufficient discussion included of the importance of the findings and their relevance to future understanding of disease processes, diagnosis or treatment?

No

Is the case presented with sufficient detail to be useful for other practitioners? Partly

Competing Interests: Dr Liou discloses that he is supported by grants from the National Institutes of Health/National Heart Blood and Lung Institute, the Ben B. and Iris M. Margolis Family Foundation of Utah, the Cystic Fibrosis Foundation, and funds from the Claudia Ruth Goodrich Stevens Endowment Fund. During the last three years, the Cystic Fibrosis Center at the University of Utah has received funds to conduct clinical trials from Cystic Fibrosis Foundation Therapeutics, Inc, the Foundation of the National Institute of Health, Gilead Sciences, Inc, Laurent Pharmaceuticals, Nivalis Therapeutics, Inc, Novartis, Proteostasis Therapeutics, Inc, Savara Pharmaceuticals and Vertex Pharmaceuticals. None of the clinical trials were related to the case reported here. Dr Liou is holder with colleagues at the $U$ of $U$ tah of a provisional patent for a novel polyketide antibiotic that is in pre-clinical research and development.

I confirm that I have read this submission and believe that I have an appropriate level of expertise to confirm that it is of an acceptable scientific standard, however I have significant reservations, as outlined above.

Author Response 08 Feb 2018

Zhe Hui Hoo, University of Sheffield, Sheffield, UK

We thank Dr Liou for the review and we will iterate the case report taking into account the 
comments.

In Sheffield whereby we only provide care for around 200 adults with CF, we only have a female adult with her exact age (in years) and her F508del/Class I mutation. Thus, to maintain the anonymity of the patient (which was the basis on which she provided consent), we could only provide an approximate age and specify that she was heterozygous for F508 mutation in the first sentence of the 'case report' section. In any case, whether the patient is 30 years of age or 33 years of age (which is the age range we consider to sit within 'early thirties') is irrelevant to the conclusion of the case report or to the interpretation of her FEV1. By stating that she has a Class II mutation (i.e. F508del) and Class I mutation in the first sentence of the 'case report' section, we have also specified that she has 'severe genotype' according to the definition of Castellani et al. J Cyst Fibros 2008, 7:179-196.

In Sheffield, we measure nebuliser adherence using I-neb (as specified in the second sentence of the 'case report' section). Electronic data capture is generally considered the 'gold standard' measure for adherence and MPR is not a "better assessment of adherence" compared to electronic data capture. The study by Siracusa et al. J Cyst Fibros 2015;14:621-6 have demonstrated that MPR data may be unreliable. In that study, ivacaftor adherence according to electronic data capture was only around $60 \%$ but MPR suggested adherence of $84 \%$. There was also no correlation between adherence data captured using electronic data capture and MPR. Since we have provided EDC adherence data, we do not think MPR data will add further information regarding her adherence.

We will clarify the trigger for the more intensive treatment period and clarify which of the treatment was used to treat an acute exacerbation. We will also provide results for her subsequent bacterial cultures and any changes in resistance patterns.

A small study using dual nebulised antibiotics has been done in 1985, as identified by the 2012 Cochrane review. We agree that any study for the treatment of pulmonary exacerbation is challenging. The STOP program in the US appears to be making breakthroughs in starting to define best practices in the treatment of pulmonary exacerbations, suggesting that such studies are difficult but not impossible to execute.

Competing Interests: No competing interests were disclosed.

Reviewer Report 30 January 2018

https://doi.org/10.5256/f1000research.14431.r30297

(C) 2018 Nazareth D et al. This is an open access peer review report distributed under the terms of the Creative Commons Attribution License, which permits unrestricted use, distribution, and reproduction in any medium, provided the original work is properly cited.

Freddy Frost 
Liverpool Heart and Chest Hospital, Liverpool, UK

Dilip Nazareth

Liverpool Heart and Chest Hospital, Liverpool, UK

Mann et al report an interesting case demonstrating that inhaled antibiotics may be useful for the treatment of acute pulmonary exacerbations in CF. The authors accurately describe the background and much of the evidence relating to the use of inhaled antibiotics in acute exacerbations including the Cochrane review of 2012. However, the Cochrane review preceded the most recent clinical trial in this field. The study demonstrated and discussed both pulmonary and renal benefits for nebulized tobramycin in the treatment of exacerbations and the authors should consider including it in the introduction. 1

In the fourth paragraph it should be clarified whether "typically one inhaled antibiotic is used at a time" refers to the routine practice in the chronic setting or previous studies in the acute setting.

The case itself is well described however the authors may wish to consider including some relevant extra information. Firstly, had the patient cultured any other organisms aside from $P$. aeruginosa in their sputum in the preceding 12 months? Secondly, were all the treatments completed at home or in the inpatient setting? Differing settings with increased physiotherapy input as an inpatient could theoretically account for some of the differences. Finally, were other adjunctive therapies such as oral corticosteroids used in the management of each exacerbation.

The discussion is balanced and recognises the limitations of the case as well as potential adverse events related to nebulised therapy. Overall, this is an interesting case worthy of publication and we wholeheartedly agree with the authors that this is a management strategy that warrants further investigation.

\section{References}

1. Al-Aloul M, Nazareth D, Walshaw M: Nebulized tobramycin in the treatment of adult CF pulmonary exacerbations.J Aerosol Med Pulm Drug Deliv. 2014; 27 (4): 299-305 PubMed Abstract | Publisher Full Text

Is the background of the case's history and progression described in sufficient detail? Partly

Are enough details provided of any physical examination and diagnostic tests, treatment given and outcomes?

Yes

Is sufficient discussion included of the importance of the findings and their relevance to future understanding of disease processes, diagnosis or treatment? Yes

Is the case presented with sufficient detail to be useful for other practitioners? Partly

Competing Interests: No competing interests were disclosed. 


\section{We confirm that we have read this submission and believe that we have an appropriate level of expertise to confirm that it is of an acceptable scientific standard, however we have significant reservations, as outlined above.}

\section{Author Response 30 Jan 2018}

Zhe Hui Hoo, University of Sheffield, Sheffield, UK

We thank Drs Frost and Nazareth for the review and very useful comments which will guide our revision of the case report.

We will include 2014 pilot study of nebulised vs IV tobramycin in the 'Introduction'. We will also alter the 4th paragraph of the 'Introduction' to clarify that the first sentence was referring to inhaled antibiotics in chronic settings whilst the second sentence referred to inhaled antibiotics in acute settings.

We will include the extra information relating to microbiology results, clarify the treatment setting (all treatments were at home except for the last course of IV antibiotics in month 11) and clarify the use of any adjunctive therapies.

Competing Interests: No competing interests were disclosed

Reviewer Report 04 January 2018

\section{https://doi.org/10.5256/f1000research.14431.r29445}

(c) 2018 Lee T. This is an open access peer review report distributed under the terms of the Creative Commons Attribution License, which permits unrestricted use, distribution, and reproduction in any medium, provided the original work is properly cited.

\section{Tim Lee}

Regional Paediatric Cystic Fibrosis Unit, Leeds Teaching Hospitals NHS Trust, Leeds, UK

This is a useful case report highlighting the potential for treating certain pulmonary exacerbations in people with cystic fibrosis with inhaled antibiotics. The background is well written. References are appropriate and balanced.

The case is well described and the adherence data prior to the exacerbations is helpful. The clinical response in terms of FEV1 is well reported and favourable by comparison to response to iv therapy.

Paragraph 2 of the "Case Report" section should in my view more clearly specify that the colomycin $2 \mathrm{MU}$ three times a day was given intravenously rather than nebulised alongside the intravenous Tazocin for 14 days in month 1 and month 4, given the overall title of the case report and the similar iv/nebulised dosages for colomycin. It would also be instructive to know whether the intravenous antibiotics were administered at home or in hospital. 
In paragraphs 3 and 4 of the "Case Report" section, it would be useful to know if the subject was also taking nebulised dornase alpha during this period, i.e. was she achieving six nebulised therapies per day? Also, if available, adherence measures during these 2 week pulses of inhaled dual antibiotic therapies would be useful, as many clinicians do have concerns that this intensity of nebulised medications may be difficult to achieve for many people with CF, despite the good clinical response seen here.

The conclusions, acknowledgements of limitations, are all well written and appropriate. In summary this case report is valuable and will be of interest to the CF community. I support publication but would recommend the clarifications I have suggested are considered.

Is the background of the case's history and progression described in sufficient detail? Yes

Are enough details provided of any physical examination and diagnostic tests, treatment given and outcomes?

Partly

Is sufficient discussion included of the importance of the findings and their relevance to future understanding of disease processes, diagnosis or treatment?

Yes

Is the case presented with sufficient detail to be useful for other practitioners?

Yes

Competing Interests: No competing interests were disclosed.

I confirm that I have read this submission and believe that I have an appropriate level of expertise to confirm that it is of an acceptable scientific standard, however I have significant reservations, as outlined above.

Author Response 04 Jan 2018

Zhe Hui Hoo, University of Sheffield, Sheffield, UK

We thank Dr Lee for the review and very useful comments which will guide our revision of the case report.

We will clarify in Paragraph 2 (and 4) of the "Case Report" section that colomycin 2MU thrice daily was given intravenously, and likely for tobramycin $480 \mathrm{mg}$ once daily (in paragraph 4).

We will also clarify the Paragraphs 2 and 3 of the "Case Report" section that once daily nebulised dornase alfa was continued throughout the dual nebulised antibiotics; and report the total number nebuliser doses taken during the 2 week pulses of dual inhaled dual antibiotic therapies. 
Competing Interests: No competing interests were disclosed.

The benefits of publishing with F1000Research:

- Your article is published within days, with no editorial bias

- You can publish traditional articles, null/negative results, case reports, data notes and more

- The peer review process is transparent and collaborative

- Your article is indexed in PubMed after passing peer review

- Dedicated customer support at every stage

For pre-submission enquiries, contact research@f1000.com 